\title{
Os desafios das atividades pedagógicas não presenciais: formação para o uso de estratégias e recursos de acessibilidade educacional
}

\author{
Ciriane Jane Casagrande da Silva ${ }^{1}$ \\ Katia de Moura Graça Paixão ${ }^{2}$ \\ Josiane Eugênio ${ }^{3}$ \\ Julieze Esquiam Gomes ${ }^{4}$ \\ Luana Zimmer Sarzi ${ }^{5}$ \\ Renata Gomes Camargo ${ }^{6}$
}

\begin{abstract}
Resumo:
Desde 2020, vivencia-se um momento de grande impacto social, em virtude da pandemia de COVID-19, na qual as condições sanitárias impossibilitaram estar na escola presencialmente. Este trabalho tem a finalidade de apresentar como o grupo de pesquisa interdisciplinar em tecnologia assistiva e inclusão contribuiu com a produção de conhecimento relacionado ao uso de recursos tecnológicos, a partir do oferecimento de oficinas sobre estratégias e recursos de acessibilidade educacional, no contexto das atividades pedagógicas não presenciais. A metodologia utilizada para a elaboração do texto embasa-se na abordagem qualitativa e se caracteriza como pesquisa descritiva e explicativa. Elucidam-se as demandas encontradas neste cenário, no Colégio de Aplicação da Universidade Federal de Santa Catarina, discute-se a importância de se utilizar estratégias e recursos tecnológicos, na elaboração de ações educacionais, que possibilitam a inclusão de todos os estudantes nos processos de ensino e aprendizagem na educação básica, especialmente os estudantes público-alvo da educação especial e apresentam-se as três oficinas oferecidas pelo grupo. Como principais resultados, tem-se que a constatação da necessidade desse tipo de formação pedagógica, como forma de qualificar a atuação dos profissionais de educação da rede pública de ensino, uma vez que observou-se a diversidade da aplicabilidade dos recursos abordados nas oficinas.
\end{abstract}

\section{Palavras-chave:}

Educação. Formação continuada. Recursos tecnológicos. Inclusão.

\footnotetext{
1 Mestra em Educação. Universidade Federal de Santa Catarina. E-mail: cirianejdasilva@gmail.com. ORCID iD: https://orcid. org/0000-0001-6458-2095.

2 Doutora em Educação. Universidade Federal de Santa Catarina. E-mail: kmgpaixao@gmail.com. ORCID iD: https://orcid. org/0000-0003-0130-3567.

3 Mestra em Educação. Universidade Federal de Santa Catarina. E-mail: josiane.eugenio@ufsc.br. ORCID iD: https://orcid. org/0000-0002-8002-0815.

4 Licenciada em Educação Especial. Prefeitura municipal de Florianópolis. E-mail: juliezeesquiam@gmail.com. ORCID iD: https://orcid.org/0000-0002-7480-7988.

5 Mestra em Educação. Universidade Federal de Santa Catarina. E-mail: luana.sarzi@ufsc.br. ORCID iD: https://orcid.org/00000002-6335-3984.

6 Doutora em Distúrbios da Comunicação Humana. Universidade Federal de Santa Catarina. E-mail: renata.g.c@ufsc.br. ORCID iD: https://orcid.org/0000-0002-0405-1994.
} 


\section{The challenges of non-face-to-face pedagogical activities: training for the use of strategies and resources of educational accessibility}

\section{Abstract:}

Since 2020, a moment of great social impact is lived deeply, in virtue of the COVID-19 pandemic, in which the sanitary conditions had disabled to be in the school actually. This work has the purpose to present as the Grupo de pesquisa interdisciplinar em tecnologia assistiva e inclusão contributed with the production of knowledge related to the use of technological resources, from the offering of workshops about strategies and resources of educational accessibility, in the actual context of the not present pedagogical activities. The methodology used for the elaboration of the text is based in the qualitative boarding and is characterized as descriptive and explicativa research. The demands found in this scene are elucidated, in the Colégio de Aplicação of the Universidade Federal de Santa Catarina, argue it importance of if using technological strategies and resources, in the elaboration of educational actions, that make possible the inclusion of all the students in the education processes and learning in the Basic Education, especially the students public-target of the Special Education and present the three workshops offered for the group. As main results, it is had that the of the necessity of this type of pedagogical formation, as form to qualify the performance of the professionals of education of the public net of education, a time that observed it diversity of the applicability of the boarded resources in the workshops.

\section{Keywords:}

Education. Continuing training. Technological resources. Inclusion.

\section{Los retos de las actividades pedagógicas no presenciales: formación para el uso de estrategias y recursos de accesibilidad educativa}

\section{Resumen:}

Desde 2020, un momento de gran impacto social se vive profundamente, en virtud del COVID-19 pandémico, en el cual las condiciones sanitarias habían inhabilitado para estar en la escuela realmente. Este trabajo tiene el propósito de presentar como el Grupo de pesquisa interdisciplinar em tecnologia assistiva e inclusión contribuyó con la producción del conocimiento, relacionada con el uso de recursos tecnológicos, con la ofrenda de talleres sobre estrategias y recursos de la accesibilidad educativa, en el contexto de las actividades pedagógicas no presentes. La metodología usada para la elaboración del texto se basa en subir cualitativo y se caracteriza como investigación descriptiva y del explicativa. Con base en la demanda encontrada en este escenario fue dilucidada en el Colégio de Aplicação de la Universidade Federal de Santa Catarina, discuten la importancia de si usan estrategias y los recursos tecnológicos, en la elaboración de las acciones educativas, que hacen posible la inclusión de todos los estudiantes en los procesos y aprender de la educación en la educación básica, especialmente de los estudiantes de la educación especial y presentan los tres talleres ofrecidos por el grupo. Como resultados principales, se tiene la constatación de la necesidad de este tipo de formación pedagógica, como forma de calificar la actuación de los profesionales de la educación de la red pública de la educación, ya que se observó la diversidad de aplicabilidad de los recursos abordados en los talleres.

\section{Palabras clave:}

Educación. Formación continua. Recursos tecnológicos. Inclusión. 


\section{Introdução}

A pandemia causada pela Covid-19, que iniciou em março de 2020, trouxe mudanças para a vida de todas as pessoas e alterou a forma como nos relacionamos com o mundo, com os outros e com a tecnologia, especialmente na educação pública brasileira, área que historicamente carece de investimentos em recursos humanos, físicos e tecnológicos, entre outros. Nesse contexto, pudemos perceber uma ampliação da desigualdade educacional, sobretudo no que diz respeito ao acesso às tecnologias e aos recursos de acessibilidade, que são de extrema importância para a garantia de participação de todos os estudantes na educação, tornando-se um desafio aos profissionais, às famílias e aos próprios estudantes para se adaptarem ao novo contexto com as ferramentas disponibilizadas até então.

Buscando atender todos os estudantes e continuar oferecendo uma educação de qualidade e inclusiva, o Colégio de Aplicação da Universidade de Santa Catarina - CA/UFSC -, localizado no município de Florianópolis-SC, está ofertando o ensino mediado pelo uso de recursos tecnológicos, denominado neste período de Atividades Pedagógicas Não Presenciais - APNPs -, autorizadas por meio da Resolução № 001/CED/2020, de julho de 2020 (CED/UFSC, 2020), oferecidas aos estudantes da educação básica, do primeiro ano do ensino fundamental ao terceiro ano do ensino médio.

Neste formato, as aulas no CA/UFSC acontecem por meio do Ambiente Virtual de Aprendizagem - AVA -, na Plataforma Moodle, composta por atividades síncronas, com transmissão ao vivo e atividades assíncronas, em período atemporal, tais como: fórum, e-mail, questionário, glossário, tarefas, blogs, troca de mensagens via Moodle, entre outros. Este processo exigiu uma gestão dos recursos próprios da escola como formação docente e técnica, empréstimo de recursos como computadores/tablets, impressão de materiais, disponibilização de pacotes de internet aos estudantes e famílias.

Durante este período conturbado que ainda estamos vivenciando, diferentes questões ainda nos preocupam ${ }^{7}$, especialmente relacionadas ao impacto deste formato na aprendizagem. Em tempos de pandemia, profissionais da educação, estagiários(as) e bolsistas de acessibilidade encontram dificuldades em oferecer atividades mediadas por recursos de tecnologia, especialmente aos estudantes público-alvo da educação especial ${ }^{8}$ que estão matriculados na educação básica.

Contudo, muitos profissionais da educação e estagiários(as), ao vivenciarem o desafio de atuar no ensino remoto, estão buscando novas tecnologias educacionais para qualificar o seu processo de ensino-aprendizagem. Motivado principalmente por essas questões, o Grupo de Pesquisa Interdisciplinar em Tecnologia Assistiva e Inclusão - GITAI -, formado no ano de 2019 pela equipe interdisciplinar do CA/UFSC, acadêmicos de graduação e pós-graduação da UFSC, além de profissionais da rede municipal de educação de Florianópolis-SC, dedicou-se a estudar como a inserção de recursos de tecnologia assistiva no ambiente escolar pode favorecer a acessibilidade dos estudantes, facilitando seu desempenho, aprendizado e desenvolvimento (GALVÃO FILHO, 2009; DELIBERATO, 2009). E, para tanto, vem realizando ações neste formato de APNPs a fim de contribuir com a produção de conhecimento relacionado à mediação tecnológica nas práticas didático-pedagógicas do contexto escolar, sob o enfoque interdisciplinar e inclusivo.

A partir dos conhecimentos adquiridos no GITAI, foi possível programar e executar atividades na área de formação de recursos humanos para o desenvolvimento de materiais, produtos, serviços de tecnologia assistiva, produção científica e acadêmica na área.

\footnotetext{
7 Segundo pesquisa realizada pela Fundação Carlos Chagas (FCC) durante a pandemia, com a participação de 14.000 professores de todo o país, a expectativa em relação à aprendizagem e a percepção de que seus alunos conseguem realizar as atividades propostas está próxima de 50\%. (FUNDAÇÃO CARLOS CHAGAS, 2020).

8 Segundo a Política Nacional de Educação Especial na perspectiva inclusiva (BRASIL, 2008) são público-alvo da educação especial os alunos com deficiência, globais de desenvolvimento e altas habilidades/superdotação.
} 
Atualmente, a tecnologia como recurso tem sido fundamental no auxílio e no desenvolvimento das atividades e, desse modo, é essencial discutir alternativas, metodologias e ferramentas tecnológicas que possibilitem acessibilidade pedagógica, além de favorecer o engajamento e a participação de todos os estudantes. Acredita-se que estratégias como jogos, plataformas, aplicativos, ferramentas de gamificação e interação podem ser alternativas facilitadoras e promotoras da inclusão educacional de todos os estudantes.

\section{Educação especial e atendimento educacional especializado nas APNPs}

No contexto das APNPs, o serviço de educação especial no CA/UFSC vem acontecendo por meio de plataformas virtuais e todo o acompanhamento pedagógico tem acontecido de modo remoto. Neste cenário, faz-se necessário estabelecer parcerias com as áreas intersetoriais do colégio, trabalhando sempre de modo articulado com os professores da sala de aula comum, para pensar, planejar e orientar estratégias pedagógicas e de acessibilidade para o ensino e aprendizado, bem como a promoção da participação dos estudantes nas atividades escolares. Também é possível promover atividades e espaços de participação com a família, bem como uma interface com os serviços setoriais da saúde e assistência social, entre outros.

A metodologia utilizada para a elaboração do texto embasa-se na abordagem qualitativa da pesquisa; quanto à finalidade define-se como uma investigação descritiva e explicativa, uma vez que pauta-se pelo detalhamento dos aspectos que seriam estudados e analisados na sequência (GIL, 2010). Frente aos desafios educacionais impostos pela pandemia no ano de 2020 e com base nas práticas e experiências da equipe do GITAI durante as APNPs, organizamos ações de formação para profissionais da educação e acadêmicos. Essas ações serão apresentadas no decorrer deste texto e dizem respeito tanto às estratégias pedagógicas como ao formato dos materiais, as inter-relações entre os conteúdos aprendidos e o cotidiano da vida escolar dos estudantes.

\section{Oficinas de estratégias e recursos de acessibilidade educacional para as APNPs: formação pedagógica oferecida pelo GITAI}

Nos encontros de estudo e formação promovidos pelo GITAI antes da pandemia, por mais que fosse discutida a educação mediada pela tecnologia, não havia a dimensão de que esta seria uma ferramenta essencial para o processo educativo. Nesse sentido,

[...] é de se esperar que a escola, tenha que 'se reinventar', se desejar sobreviver como instituição educacional. É essencial que o professor se aproprie da gama de saberes advindos com a presença das tecnologias digitais da informação e da comunicação para que estes possam ser sistematizados em sua prática pedagógica. A aplicação e mediação que o docente faz em sua prática pedagógica do computador e das ferramentas multimídia em sala de aula, depende, em parte, de como ele entende esse processo de transformação e de como ele se sente em relação a isso, se ele vê todo esse processo como algo benéfico, que pode ser favorável ao seu trabalho, ou se ele se sente ameaçado e acuado por essas mudanças. (SOUZA et al., 2011, p. 20).

Não há previsão do tempo em que perdurará esse cenário, mas neste momento é possível perceber que já houve uma grande transformação e que até mesmo houve quebras de paradigmas e medos frente ao uso das tecnologias no ambiente educacional, entendendo que não havia outra possibilidade que não fosse o enfrentamento e a incorporação desta no dia a dia do trabalho docente. 
Diante de tantos desafios neste novo formato, é importante pensar também de que maneira podemos tornar mais interativo e inclusivo esse espaço virtual da sala de aula, ou seja, de que modo pode-se ampliar a participação dos estudantes.

[...] na sociedade da informação, todos estamos reaprendendo a conhecer, a comunicar-nos, a ensinar; reaprendendo a integrar o humano e o tecnológico, a integrar o individual, o grupal e o social. É importante conectar sempre o ensino com a vida do aluno. Chegar ao aluno por todos os caminhos possíveis: pela experiência, pela imagem, pelo som, pela representação (dramatizações, simulações), pela multimídia, pela interação on-line e off-line. (MORAN, 2000, p. 61).

A formação dos professores neste sentido está para além dos conhecimentos técnicos sobre computadores ou softwares, identificando as dificuldades envolvidas neste processo, refletindo sobre sua prática e buscando alternativas para integrar as diferentes mídias e recursos ao conhecimento disponibilizado em aulas e interações virtuais.

Assim, neste trabalho, apresentamos as três oficinas organizadas pelo GITAI, realizadas por meio do Sistema de Conferência Web (RNP) e sua importância para a produção de conhecimentos sobre processos educativos mediados por tecnologia para as atividades de ensino no formato não presencial, de estudantes na educação básica. Segue, abaixo, o quadro com a apresentação dos temas desenvolvidos nas oficinas:

Figura 1: Temas das oficinas

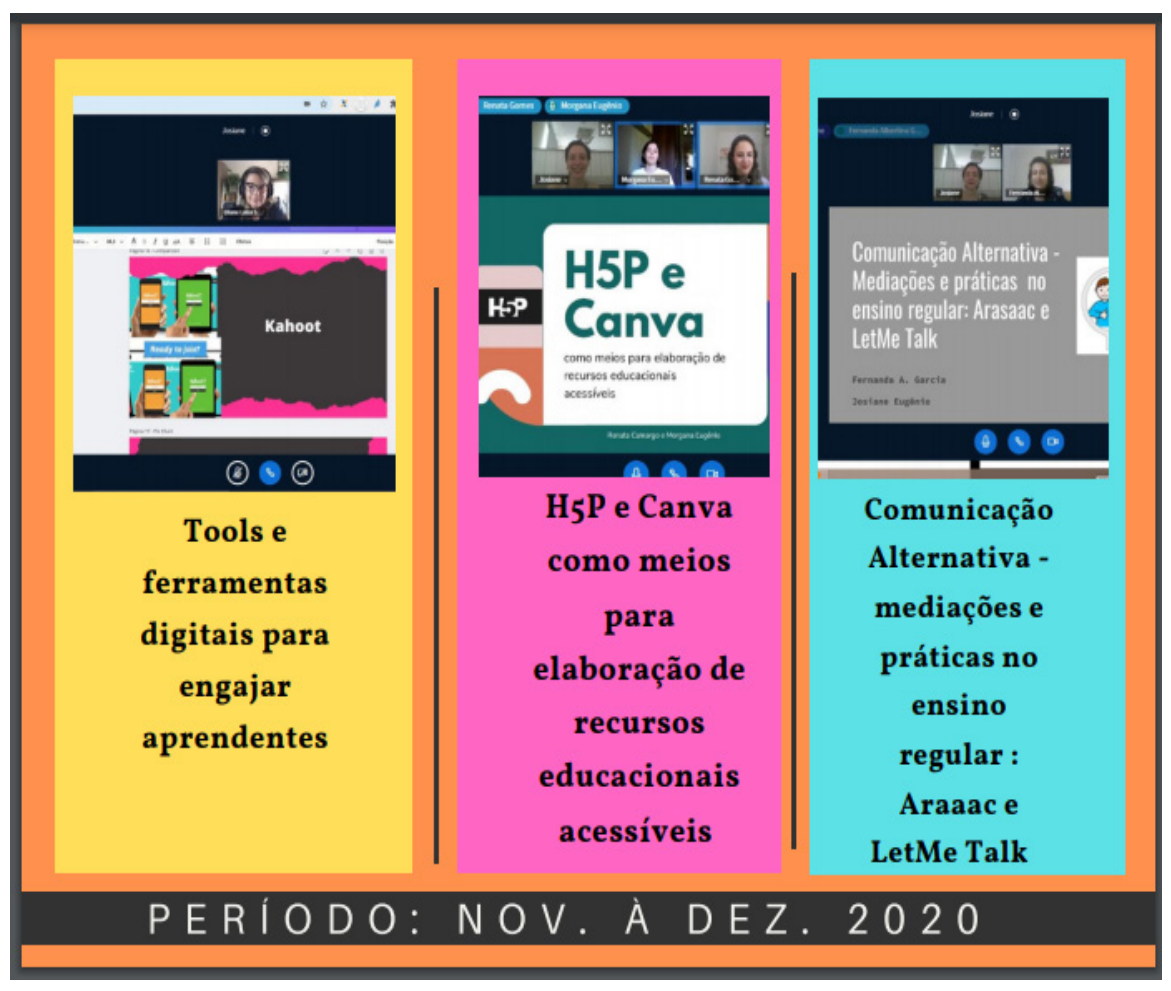

Fonte: Elaborada pelas autoras (2021)

\section{Tools e ferramentas digitais}

Neste encontro, foram apresentadas várias possibilidades de recursos e ferramentas digitais que podem ser utilizadas durante os momentos síncronos para aumentar a participação, a produção 
de materiais didáticos, como também acompanhar o processo de aprendizagem dos estudantes. Para ampliar as formas de levantamento dos conhecimentos apropriados pelos estudantes e orientar os professores no planejamento das aulas durante este período não presencial, entre as ferramentas apresentadas nas oficinas destacaremos algumas possibilidades que incluem elementos visuais e sonoros, para além dos textuais, como é o caso do site $\operatorname{Vocaroo~}^{9}$ Esse site possibilita gravar a voz e compartilhar o link por e-mail, mensagem, entre outros, o que contribui para a participação de estudantes que ainda não estão alfabetizados. Outra ferramenta interessante é o $E d p u z z l e^{10}$, por exemplo, pois possibilita que o professor edite um vídeo, inserindo sua própria voz e adicionando perguntas a respeito de elementos do vídeo.

Outra ferramenta apresentada que agrega elementos textuais, visuais e sonoros é o site Learningapps, ${ }^{11}$ no qual é possível criar atividades interativas que podem ser realizadas em diversos dispositivos.

Para a criação de questionários interativos e gamificados, uma ferramenta apresentada foi a plataforma Kahoot! $!^{12}$ que possui um formato parecido com jogos de quizzes, em que as questões corretas valem pontos, de uso bastante intuitivo pelo professor e atrativo aos estudantes. Na versão $a p p$, os estudantes poderão optar pela leitura em voz alta da pergunta e das alternativas, uma a uma, destacando qual parte está sendo lida, para que os jogadores possam escolher a sua própria resposta.

\section{H5P e Canva como meios para elaboração de recursos educacionais acessíveis}

A oficina H5P e Canva, como meios para elaboração de recursos educacionais acessíveis, teve por objetivo apresentar as possibilidades para elaboração de recursos educacionais acessíveis e gratuitos nos sites H5P e no Canva.

O H5P (HTML5 Package) está embutido na configuração da plataforma Moodle, da qual os profissionais da educação e estagiários que trabalham no CA/UFSC têm acesso. Na oficina, tiveram a oportunidade de conhecer novas possibilidades de uso desta ferramenta, bem como aperfeiçoar os conhecimentos que já dispunham no ensino presencial.

O Canva é uma plataforma de design gráfico que permite aos usuários criar conteúdos visuais diversificados. Além disso, essa plataforma disponibiliza muitos layouts de materiais que podem ser modificados pelos professores, de acordo com a sua necessidade.

Uma das possibilidades apresentadas foi a utilização do H5P para construção de jogos da memória. A escolha por apresentar este recurso pelas ministrantes da oficina foi em virtude deste jogo propiciar a abordagem de diversos conteúdos e áreas do conhecimento. A demonstração realizada foi de um jogo de memória sobre pontos turísticos importantes em diferentes cidades do mundo, elaborado para a disciplina de Geografia. Já sobre a utilização do Canva, um dos recursos apresentados foi a possibilidade de elaboração de um mapa conceitual, utilizando apenas imagens, criadas a partir do recurso ícone disponível neste site. 
A última oficina ofertada trouxe uma discussão teórico-prática sobre os recursos de Tecnologia Assistiva - TA -, mais especificamente voltados para a Comunicação Suplementar e/ou Alternativa - CSA.

Com a oficina, foi possível conhecer um pouco mais acerca do que é a CSA, como ela se constitui, quais as estratégias e de que forma proporciona acessibilidade a variadas formas de comunicação, o que pode acontecer por meio de recursos como pranchas e/ou cartões de comunicação com palavras, imagens e/ou fotografias impressas, vocalizadores, softwares de varredura e controladores oculares de alta tecnologia.

Para isso, foram explorados os recursos e sistemas de CSA do Centro Aragonês de Comunicação Aumentativa e Alternativa - ARASAAC -, que é uma página na internet elaborada pelo governo de Aragão, na Espanha, para a construção de pictogramas e pranchas de CSA em diferentes línguas. Além disso, o site apresenta uma gama de materiais previamente disponibilizados que podem ser usados como recursos de aprendizagem para diferentes estudantes e de diversas faixas etárias.

Outro recurso explorado na Oficina foi o LetMe Talk, um aplicativo gratuito de CSA que faz uso do sistema pictográfico do ARASAAC e pode ser utilizado em smartphones e tablets com sistemas Android e IOS. Com esse recurso é possível dialogar com o estudante usuário do CSA a partir de pranchas pré-estruturadas e/ou ancorar novas pranchas ao sistema. Ambos os recursos apresentados na oficina ampliam a acessibilidade, comunicação e interação com estudantes com necessidades complexas de comunicação.

Tais recursos podem beneficiar, por exemplo, os estudantes público-alvo da educação especial, com deficiência e/ou Transtorno do Espectro Autista - TEA -, tendo em vista que podem apresentar restrições motoras, intelectuais e/ou de comportamento que podem interferir em sua comunicação.

\section{Aplicabilidade dos recursos e métodos apresentados nas oficinas nas APNPs}

A aplicabilidade das oficinas realizadas pode ser percebida em diferentes espaços e segmentos. Uma das professoras de educação especial, em conjunto com a pedagoga de educação especial, que atuavam no ensino médio, por exemplo, a partir da participação na oficina Tools e ferramentas digitais, desenvolveram junto com a docente responsável pela disciplina de Sociologia, um Kahoot! sobre os sistemas econômicos, a fim de ampliar a interação com dois estudantes com Transtorno do Espectro Autista que participavam desta aula.

Durante este encontro, foi compartilhada a tela do jogo e solicitado que cada estudante escolhesse oralmente a resposta, que era registrada pela pedagoga no site. A cada questão respondida, a professora discutia com cada um deles a resposta e retomava alguns conceitos trabalhados em aula, a fim de obter mais elementos sobre a compreensão do conteúdo, tendo em vista que apenas a participação na aula síncrona com toda a turma e com os trabalhos entregues, a efetiva participação dos alunos nas aulas e uma análise mais detalhada do processo de aprendizagem, não era possível para a professora de Sociologia. Outro ponto que destacamos foi que a partir deste jogo criou-se um ambiente descontraído e acolhedor para os estudantes, para além do conteúdo da disciplina, pois puderam também contar um pouco sobre como estavam lidando com as APNPs e vivendo durante o período de pandemia.

Outro exemplo do alcance desta oficina foi o site Powtoon ${ }^{13}$, que é um espaço gratuito para produção de vídeo e foi um dos recursos apresentados. Em virtude da versatilidade e linguagem

13 Disponível em: https://www.powtoon.com/. Acesso em: 10 maio 2020. 
intuitiva do site, ele foi escolhido por um estudante com deficiência física que frequentava o ensino médio em 2020. Dentre três opções apresentadas pela professora de educação especial no Atendimento Educacional Especializado - AEE -, para a elaboração de um vídeo, o estudante selecionou esse site. Tal proposta o auxiliou na realização de trabalhos escolares solicitados pelos demais professores, envolvendo este recurso.

No exemplo dado, quanto à utilização de um site para gravação de vídeos educacionais, pode-se vislumbrar principalmente a contemplação das inteligências linguística e espacial, uma vez que o estudante elaborou frases para compor o vídeo e selecionou imagens vinculadas ao seu conteúdo, contemplando ambas as inteligências, respectivamente. Logo, a utilização desses recursos pode contribuir com as oportunidades de favorecimento das diferentes inteligências dos estudantes.

A utilização dos recursos relacionados à CSA apresentados na oficina sobre esta temática também se efetivou em diferentes momentos nas APNPs. Com os conhecimentos oportunizados na oficina, foi possível elaborar materiais didático-pedagógicos, como histórias ilustradas, jogos da memória, pranchas para diálogo utilizados no AEE com estudantes usuários desses e outros sistemas alternativos de comunicação.

\section{Considerações finais}

Nesse momento pandêmico ainda vivenciamos momentos de incerteza, e, sendo assim, é necessário buscar novos caminhos, novos conhecimentos, e todo esse movimento nos traz muitos aprendizados. Percebemos que os benefícios do desenvolvimento destas aprendizagens ultrapassam o âmbito das APNPs, uma vez que com o retorno das aulas presenciais os profissionais da educação poderão continuar acessando parte dos recursos utilizados na atuação não presencial. E, ainda, essas aprendizagens podem ser úteis aos estudantes em atividades que realizam no âmbito extraescolar.

É possível perceber que, neste contexto remoto, apresenta-se ainda o desafio de coordenar o uso de diferentes tecnologias e a alfabetização digital desses estudantes e suas famílias, que vivenciam diferentes desafios e dificuldades de adaptação ao meio virtual para a realização das atividades. Experienciar este novo modelo de escolarização requer, portanto, novas/outras habilidades e competências, para gestão e organização de recursos e serviços a serem oferecidos.

Ressaltamos que a formação ofertada pelo GITAI, vem ao encontro da proposta que identifica o Colégio de Aplicação da UFSC, como escola experimental, que objetiva oportunizar formação e compartilhamento de experiências pedagógicas para professores da rede pública de ensino e aos acadêmicos dos cursos de Licenciatura e Educação, por meio dos estágios curriculares, segundo as exigências da Lei no 9394, de 20 de dezembro de 1996 (BRASIL, 1996).

Durante as oficinas, estavam presentes professores de Línguas, Educação Especial, profissionais da educação, estagiários de acessibilidade, acadêmicos da UFSC, entre outros, que puderam se beneficiar dos conhecimentos oferecidos e qualificar o ensino em suas áreas de atuação.

Desse modo, esta ação abrange diferentes áreas do conhecimento e demonstrou como esses recursos de tecnologia podem ser aplicados no âmbito da educação e o quanto se faz necessário continuar ofertando oportunidades como esta, na formação de recursos humanos em prol de uma educação de qualidade, gratuita e acessível a todos. Nesse sentido, as oficinas, no presente ano (2021), continuam sendo oferecidas em sua segunda edição, com o intuito de alcançar outros profissionais e contextos de atuação. 


\section{Referências}

BRASIL. Ministério da Educação. Secretaria de Educação Especial. Política Nacional de Educação Especial na perspectiva da educação inclusiva. Brasília, DF: MEC, 2008. Disponível em: http://portal.mec.gov.br/arquivos/pdf/politicaeducespecial.pdf. Acesso em: 07 mar. 2015.

BRASIL. Lei de Diretrizes e Bases da Educação Nacional. Lei no 9.394, de 20 de dezembro de 1996. Brasília, DF, 1996.

CED/UFSC - CENTRO DE CIÊNCIAS DA EDUCAÇÃO. UNIVERSIDADE FEDERAL DE SANTA CATARINA. Resolução n. ${ }^{\circ}$ 001/CED/2020, de 02 de julho de 2020. CED/UFSC, 2020. Disponível em: https://ced.ufsc.br/2020/07/03/ resolucao-n-o-001ced2020-de-02-de-julho-de-2020/. Acesso em: 10 nov. 2020

DELIBERATO, Débora. Uso de Expressões Orais Durante a Implementação do Recurso de Comunicação Suplementar e Alternativa. Revista Brasileira de Educação Especial, Marília, v. 15, n. 3, p. 369-388, 2009.

FUNDAÇÃO CARLOS CHAGAS (FCC). Educação escolar em tempos de pandemia na visão de professoras/es da Educação Básica. Informe no. 1, 2020. Disponível em: https://www.fcc.org.br/fcc/educacao-pesquisa/educacao-escolar-em-tempos-depandemia-informe-n-1. Acesso em: 10 nov. 2020.

GALVÃO FILHO, Teófilo Alves. Tecnologia assistiva para uma escola inclusiva: apropriação, demanda e perspectivas. 2009. Tese (Doutorado em Educação) - Universidade Federal da Bahia, Bahia, 2009.

GIL, Antônio Carlos. Como elaborar projetos de pesquisa. 5. ed. São Paulo: Atlas, 2010.

MORAN, José Manuel. A integração das tecnologias na educação. 2000. Disponível em: https://www.livrosgratis.com. br/ler-livro-online-39427/integracao-das-tecnologias-na-educacao--salto-para-o-futuro. Acesso em: 05 maio 2021.

SOUSA, Robson Pequeno de; MOITA, Filomena Maria Gonçalves da Silva Cordeiro; CARVALHO, Ana Beatriz Gomes. Tecnologias digitais na educação. Campina Grande: EDUEPB, 2011.

Data de submissão: 15/05/2021

Data de aceite: 20/06/2021 